\title{
Diffuse Axonal Injury and Early Intracranial Sequelae in Severe Head Injury
}

\author{
Minoru SHIGEMORI, Takashi TOKUTOMI, Shinken KURAMOTO, \\ Takumi MORIYAMA, Naomi KIKUCHI and Yasuyuki SASAGURI*
}

\author{
Departments of Neurosurgery and *Pathology, Kurume University \\ School of Medicine, Kurume, Fukuoka
}

\begin{abstract}
The importance of diffuse axonal injury (DAI) and early intracranial sequelae was studied in $107 \mathrm{pa}-$ tients with diffuse and focal brain injuries. Comprehensive neuropathological study was also undertaken in $\mathbf{2 4}$ fatal patients. The mortality rate was clearly the highest in traumatic subarachnoid hemorrhage, followed by acute subdural hematoma, cerebral contusion with delayed hematoma formation, traumatic intracerebral hematoma, diffuse cerebral swelling, DAI with classical features, and finally nearly normal on computed tomographic scans. The mean flow velocities in the middle cerebral artery recorded by transcranial Doppler ultrasound were variable in diffuse brain injury, but commonly decreased on the hematoma side depending on increased intracranial pressure and decreased cerebral perfusion pressure in focal brain injury. Deep-seated hemorrhagic lesions did not expand in diffuse brain injury, but sizable hematoma developed within 24 hours in focal brain injury. The platelet count was significantly lower in patients with poor outcomes in focal brain injury. Histological evidence of classical DAI was found in eight $(50 \%)$ of 16 cases with focal brain injury. DAI of varying severity is the common subjacent lesion in patients with severe head injury, but the final outcome varies greatly with different lesion types.
\end{abstract}

Key words: diffuse axonal injury, outcome, cerebral circulation, intracerebral hematoma

\section{Introduction}

Head-injured patients can be classified into diffuse and focal brain injury types. ${ }^{8,14)}$ The outcome for patients with severe head injury fundamentally depends on the severity of the direct injury, diffuse axonal injury (DAI). ${ }^{2,3,9,14,15,21)}$ The sequence of secondary insults such as increased intracranial pressure (ICP), intracranial hemodynamic disorders, and hematoma formation, which may occur depending on the lesion type, also influence the final outcome. ${ }^{6.10 .14-16)}$ However, the extent of DAI and early intracranial sequelae in individuals with diffuse and focal brain injuries are not fully understood. ${ }^{5,6,14,16,18)}$ The present study investigated the association of DAI and early intracranial sequelae in patients with severe head injury.

Received August 20, 1990; Accepted December 14,

\section{Materials and Methods}

\section{Clinical study}

The study included 107 patients admitted to our hospital within 6 hours of severe head injury between 1982 and 1990 . They were divided into diffuse $(n=$ $44)$ and focal brain injury $(n=63)$ groups according to the type of brain damage. ${ }^{8,14)}$ All patients had Glasgow Coma Scale (GCS) scores ${ }^{22)}$ of 7 or less on admission and no serious multiple injuries. Based on the principal findings of the initial computed tomographic (CT) scan, the diffuse brain injury group was subdivided into four types: DAI with classical features ${ }^{2,3,9,21)}(\mathrm{n}=16)$, diffuse cerebral swelling $(D C S)^{14)}(n=8)$, traumatic subarachnoid hemorrhage in the basal subarachnoid cisterns $(\mathrm{TSAH})^{20)}(\mathrm{n}=10)$, and nearly normal $(\mathrm{n}=10)$. Patients in this group were between 3 and 77 years old (mean 35 years). Similarly, the focal brain injury group was subdivided into three types: traumatic intracerebral hematoma $(\mathrm{ICH})(\mathrm{n}=23)$, cerebral contusion with delayed hematoma formation $(\mathrm{DICH})$ 
$(\mathrm{n}=14)$, and acute subdural hematoma (SDH) $(n=26)$. These patients were between 5 and 80 years old (mean 44 years).

The ICP was monitored in 40 patients using a catheter tip transducer (ITC/b, Gaeltec, England) in the extradural space. The systemic arterial blood pressure was also recorded simultaneously from the radial artery with a pressure transducer (P50, Statham, U.S.A.) to calculate the cerebral perfusion pressure (CPP). ${ }^{19}$

To evaluate the intracranial hemodynamics, the blood flow velocity in the middle cerebral artery (MCA) was recorded in 83 patients using transcranial Doppler ultrasound (TC2-64 and transscan, EME, Germany) under end-tidal carbon dioxide monitoring. The mean flow velocities in the bilateral MCA trunks were calculated from five measurements. ${ }^{11)}$ The main MCA trunk was identified by varying the depth of the range gate and the probe tilt transtemporally. ${ }^{1)}$ The mean flow velocity in the MCA of 26 healthy adults was $67.3 \pm 13.0 \mathrm{~cm} / \mathrm{sec} .{ }^{191}$ The pulsatility amplitude between the systolic and diastolic flow velocities (S/D) was also measured.

The development of intracerebral hematoma was investigated using follow-up CT scanning, and platelet count, fibrinogen, fibrinogen degradation product (FDP), activated partial thromboplastin time (APTT), and prothrombin time (PT) were measured in 58 patients.

The outcome 3 months after head injury was evaluated by the Glasgow Outcome Scale. ${ }^{12}$ Statistical analyses used the nonparametric KruskallWallis $\mathrm{H}$ test.

\section{Neuropathological study}

Comprehensive neuropathological studies were made of 24 patients with fatal head injuries, including 21 males and three females aged between 6 and 78 years. All patients had been injured in road traffic accidents. All lost consciousness immediately on impact and remained comatose until death. On admission, 17 patients $(71 \%)$ had a GCS score of 3 or 4. The lesions included eight diffuse brain injuries (2 classical DAI, 4 TSAH, and 2 DCS) and 16 focal brain injuries (ICH or SDH). Survival time ranged from 16 hours to 21 days, with a mean of 4 days in diffuse brain injury and 7 days in focal brain injury. All TSAH patients died within the first 2 days.

The brain was removed and fixed in $10 \%$ formol saline for at least 3 weeks before dissection. The cerebral hemispheres, cerebellum, and brainstem were cut into approximately $10 \mathrm{~mm}$ sections in the standard coronal or axial planes for gross examina- tion. Representative slices obtained from the corpus callosum (genu, body, and splenium), internal capsule, parahippocampal gyri, cerebellum, and brainstem were embedded in paraffin, cut into $10 \mu \mathrm{m}$ sections, and stained with hematoxylin and eosin (HE) and by the Bodian method for microscopic examination. The presence or absence of skull fractures and transtentorial herniation was also evaluated.

\section{Results}

\section{Clinical findings}

Seventeen $(38.6 \%)$ of 44 patients with diffuse brain injury and $29(46.0 \%)$ of 63 patients with focal brain injury had a GCS score of 3 or 4 on admission. The incidence of low GCS scores was highest in SDH (57.7\%), followed by TSAH (50.0\%), ICH (47.8\%), classical DAI $(43.8 \%), \quad$ DCS $(37.5 \%), \quad$ DICH $(21.4 \%)$, and nearly normal $(20.0 \%)$. The incidence of mortality was clearly in the order: TSAH $(70.0 \%)$, SDH $(65.4 \%)$, DICH $(64.3 \%)$, ICH $(47.8 \%)$, DCS $(37.5 \%)$, classical DAI $(31.3 \%)$, and nearly normal $(10.0 \%)$. The incidence of good recovery and moderate disability was similar to the inverse of the mortality order.

The ICP in the diffuse brain injury group was generally lower than in the focal brain injury group, except for the DCS patients. The mean MCA flow velocities in 33 patients with diffuse brain injury commonly decreased bilaterally on admission with no significant difference between right and left. Patients with classical DAl, TSAH, and DCS demonstrated a relatively rapid increase in flow velocity for 7 days after head injury, but no significant change in S/D occurred. However, 50 patients with focal brain injury frequently demonstrated lower flow velocities on the hematoma side than contralaterally on admission. The S/D was also significantly higher on the lesion side. The flow velocities decreased when the ICP increased, but returned to normal when the ICP decreased after hematoma evacuation. The flow velocity was also lower in patients with lower GCS scores irrespective of the lesion type. Decreases in the mean MCA flow velocities depended significantly on increased ICP and decreased CPP in focal brain injury (Tables 1 and 2).

The deep-seated hemorrhagic lesions commonly seen in patients with diffuse brain injury did not expand on serial CT scans. These patients frequently developed diffuse brain atrophy later. However, sizable intracerebral hematoma developed within 24 hours after head injury in DICH patients (Fig. 1). The platelet count in both groups decreased on days 1-3 after head injury but increased again to normal 
Table 1 ICP and MCA flow velocity

\begin{tabular}{ccc}
$\mathrm{ICP}$ & \multicolumn{2}{c}{ Flow velocity $(\mathrm{cm} / \mathrm{sec})$} \\
$(\mathrm{mmHg})$ & Diffuse brain injury & Focal brain injury \\
$\leqq 20$ & $97.2 \pm 51$ & $70.6 \pm 27$ \\
$21-30$ & $98.0 \pm 41$ & $78.2 \pm 24$ \\
$31-40$ & $87.0 \pm 62$ & $55.0 \pm 24^{*}$ \\
$41-60$ & $81.0 \pm 28$ & $45.7 \pm 14^{* *}$ \\
$61 \leqq$ & - & $18.8 \pm 99^{* *}$ \\
$* \mathrm{p}<0.05, * * \mathrm{p}<0.01$ versus control value $(67.3 \pm$ \\
$13 \mathrm{~cm} / \mathrm{sec})$.
\end{tabular}

Table 2 CPP and MCA flow velocity

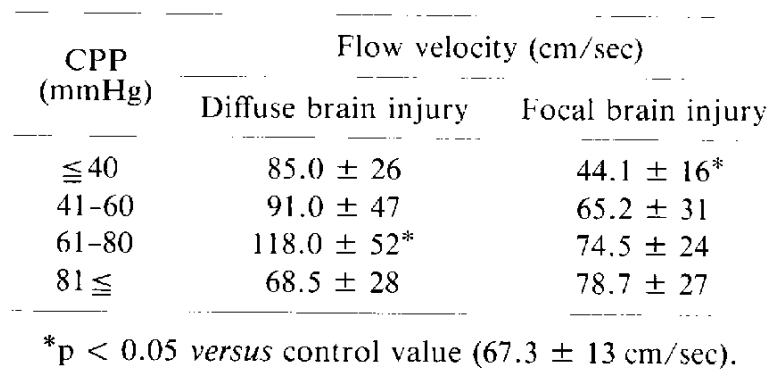

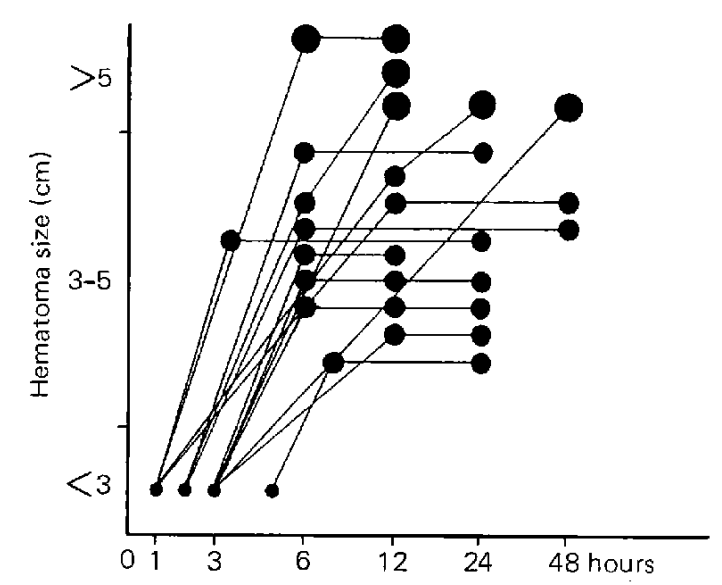

Fig. 1 Development of a sizable intracerebral hematoma detected by serial CT scanning in patients with DICH.

within 7 days. There was no significant difference in platelet counts between patients with good and unfavorable outcomes in diffuse brain injury. The platelet count was significantly lower in patients with focal brain injury, whose outcomes were also significantly related (Fig. 2). APTT and PT levels remained within the normal range for 7 days after in-

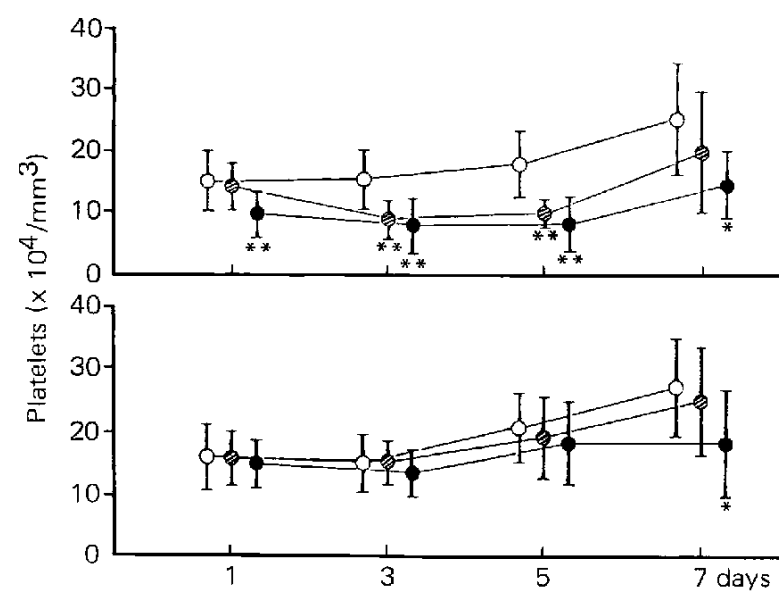

Fig. 2 Platelet counts and outcome in focal (upper, $\mathrm{n}=34$ ) and diffuse brain injury (lower, $\mathrm{n}=$ 24) groups. $O:$ good outcome, poor outcome, : died. ${ }^{*} \mathrm{p}<0.05,{ }^{*} \mathrm{p}<0.01$ versus good outcome group.

jury. The fibrinogen level tended to increase gradually within 7 days and the FDP level peaked on the first day, but all remained within normal limits. There was no significant correlation between their values, lesion types, and patient outcomes.

\section{Il. Neuropathological findings}

The gross neuropathological findings in 24 subjects are summarized in Tables 3 and 4 . Six cases of diffuse brain injury and 14 of focal brain injury had skull fractures visible at autopsy. The most frequent contusion sites were the frontal poles followed by the temporal poles, which were seen in all focal brain injury and two diffuse brain injury cases. One patient had contusion foci in the cerebellum. Seventeen patients had signs of increased ICP, manifested by pressure necrosis in unilateral or bilateral parahippocampal gyri. Macroscopic lesions in the corpus callosum present in 11 cases were all hemorrhagic and eccentric. In six cases, gross hemorrhages were seen in the ventral or dorsal brainstem, involving the midbrain, the rostral part of the pons, or both. The hemorrhagic lesions were frequently in the ventral brainstem in focal brain injury, but were generally localized in the dorsal brainstem in diffuse brain injury. Only one case had a macroscopically normal brainstem. Eleven patients had axonal retraction balls in the internal capsule, corpus callosum, or the brainstem but none were TSAH cases. Eight $(50 \%)$ of 16 cases with focal brain injury had characteristic features of DAI (Fig. 3). 
Table 3 Pathological findings in diffuse brain injury

\begin{tabular}{|c|c|c|c|c|c|c|c|c|c|c|c|}
\hline \multirow{3}{*}{$\begin{array}{l}\text { Case } \\
\text { No. }\end{array}$} & \multirow{3}{*}{$\begin{array}{c}\text { Lesion } \\
\text { type }\end{array}$} & \multirow{3}{*}{$\begin{array}{c}\text { Skull } \\
\text { fracture }\end{array}$} & \multirow{3}{*}{$\begin{array}{l}\text { Tentorial } \\
\text { herniation }\end{array}$} & \multirow{3}{*}{$\begin{array}{l}\text { Lesion in } \\
\text { corpus } \\
\text { callosum }\end{array}$} & \multicolumn{4}{|c|}{ Lesion in brainstem* } & \multicolumn{3}{|c|}{ Axonal retraction balls } \\
\hline & & & & & \multicolumn{2}{|c|}{ Ventral } & \multicolumn{2}{|c|}{ Dorsal } & \multirow{2}{*}{$\begin{array}{l}\text { Internal } \\
\text { capsule }\end{array}$} & \multirow{2}{*}{$\begin{array}{l}\text { Corpus } \\
\text { callosum }\end{array}$} & \multirow{2}{*}{ Brainstem } \\
\hline & & & & & Rt & $\mathrm{Lt}$ & $\mathrm{Rt}$ & $\mathrm{Lt}$ & & & \\
\hline 1 & DAI & + & + & + & ++ & & ++ & & + & & + \\
\hline 2 & DAI & & & + & & & +++ & & + & + & + \\
\hline 3 & TSAH & & & & + & + & ++ & & & & \\
\hline 4 & TSAH & + & & & & & + & + & & & \\
\hline 5 & TSAH & + & & + & & & + & + & & & \\
\hline 6 & TSAH & + & & & & & + & + & & & \\
\hline 7 & $\mathrm{DCS}$ & + & + & & + & + & ++ & & & & \\
\hline 8 & DCS & + & + & & & & + & & + & + & + \\
\hline
\end{tabular}

${ }^{*}+$ : microscopic hemorrhage, ++ : small hemorrhagic foci, +++ : gross hemorrhage.

Table 4 Pathological findings in focal brain injury

\begin{tabular}{|c|c|c|c|c|c|c|c|c|c|c|c|}
\hline \multirow{3}{*}{$\begin{array}{l}\text { Case } \\
\text { No. }\end{array}$} & \multirow{3}{*}{$\begin{array}{l}\text { Lesion } \\
\text { type }\end{array}$} & \multirow{3}{*}{$\begin{array}{c}\text { Skull } \\
\text { fracture }\end{array}$} & \multirow{3}{*}{$\begin{array}{c}\text { Tentorial } \\
\text { herniation }\end{array}$} & \multirow{3}{*}{$\begin{array}{l}\text { Lesion in } \\
\text { corpus } \\
\text { callosum }\end{array}$} & \multicolumn{4}{|c|}{ Lesion in brainstem* } & \multicolumn{3}{|c|}{ Axonal retraction balls } \\
\hline & & & & & \multicolumn{2}{|c|}{ Ventral } & \multicolumn{2}{|c|}{ Dorsal } & \multirow{2}{*}{$\begin{array}{l}\text { Internal } \\
\text { capsule }\end{array}$} & \multirow{2}{*}{$\begin{array}{l}\text { Corpus } \\
\text { callosum }\end{array}$} & \multirow{2}{*}{ Brainstem } \\
\hline & & & & & $\mathrm{Rt}$ & Lt & $\mathrm{Rt}$ & $\mathrm{Lt}$ & & & \\
\hline 1 & $\mathrm{ICH}$ & + & + & & +++ & +++ & ++ & ++ & & & \\
\hline 2 & $\mathrm{ICH}$ & + & + & & ++ & + & & & & & \\
\hline 3 & $\mathrm{ICH}$ & + & + & & ++ & ++ & ++ & ++ & & & + \\
\hline 4 & $\mathrm{ICH}$ & + & + & + & +++ & +++ & & & + & + & \\
\hline 5 & $\mathrm{ICH}$ & + & + & + & +++ & + & +++ & ++ & + & & \\
\hline 6 & $\mathrm{ICH}$ & + & & + & + & + & & & & & \\
\hline 7 & $\mathrm{ICH}$ & + & + & + & + & +++ & & ++ & & & + \\
\hline 8 & $\mathrm{ICH}$ & + & + & & + & ++ & + & & & & \\
\hline 9 & $\mathrm{SDH}$ & + & + & + & ++ & ++ & ++ & ++ & + & & \\
\hline 10 & $\mathrm{SDH}$ & + & & & & & & & & & \\
\hline 11 & $\mathrm{SDH}$ & + & + & & ++ & ++ & & ++ & & & + \\
\hline 12 & SDH & & + & + & ++ & ++ & & ++ & & & \\
\hline 13 & $\mathrm{SDH}$ & & + & & ++ & ++ & & & + & & \\
\hline 14 & $\mathrm{SDH}$ & + & + & & + & + & & & & & \\
\hline 15 & $\mathrm{SDH}$ & + & + & + & ++ & ++ & & + & & & \\
\hline 16 & $\mathrm{SDH}$ & + & + & + & +++ & +++ & ++ & + & + & & \\
\hline
\end{tabular}

* + : microscopic hemorrhage, ++ : small hemorrhagic foci, +++ : gross hemorrhage.

\section{Discussion}

Our results demonstrate a clear order in the outcome for patients that depends on the lesion type. TSAH, SDH, and DICH were the worst types of severe head injury. Lesions possibly causing secondary insults were DCS in diffuse brain injury and DICH in focal brain injury. Hematoma formation is generally known to be a most important prognostic indicator for patients with severe head injury. ${ }^{14,15}$ Abnormal coagulation and fibrinolysis are also frequent complications in severe head injury. ${ }^{13,17)}$ Thrombocy- topenia was commonly seen within a few days of head injury and directly correlated with poor outcome in focal brain injury. Other hemological factors were not correlated with the lesion type or outcome. Hematoma developed within 24 hours after head injury in focal brain injury. Abnormal hemostasis in head-injured patients has been related to the development of disseminated intravascular coagulation (DIC), ${ }^{13\}}$ but we found no definite evidence of DIC. Local platelet exhaustion by hematoma formation or restorative processes may have caused the thrombocytopenia although the exact 

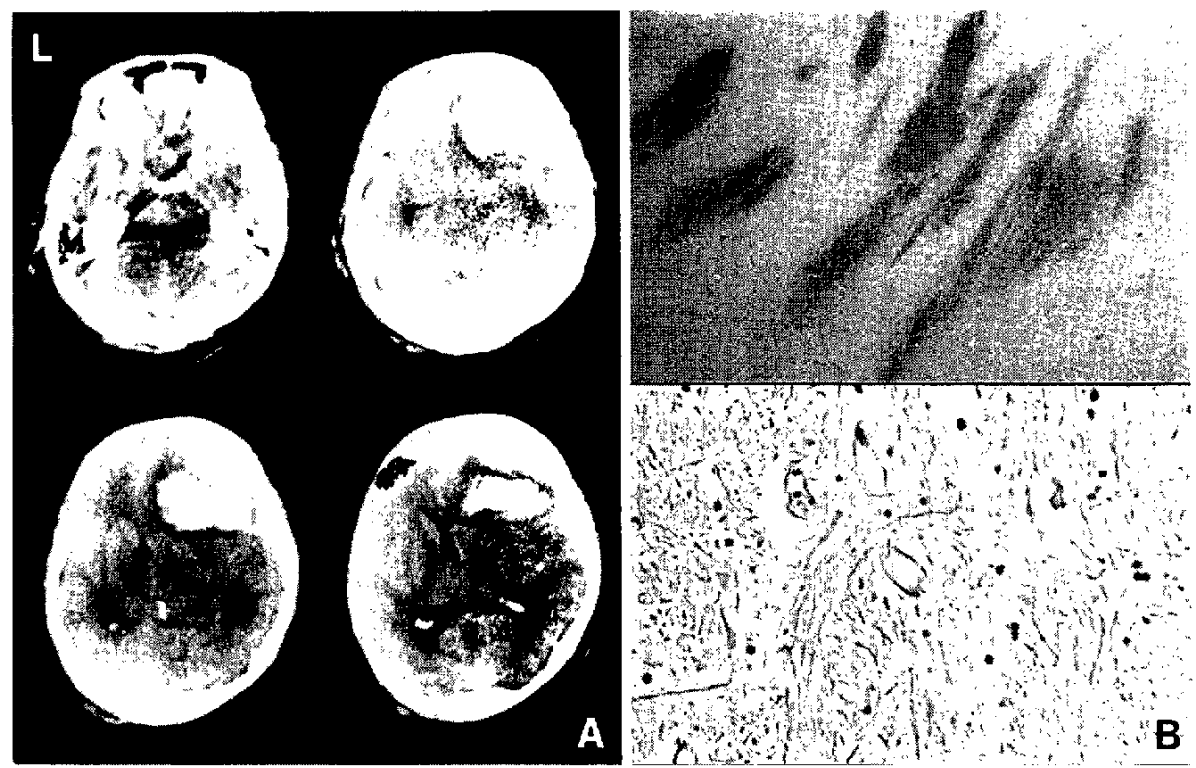

Fig. 3 A 59-year-old female with focal brain injury (Case 5). A: Initial CT scans, showing contusional hemorrhage in the right frontal lobe. B: Photomicrographs at autopsy, showing linear hemorrhagic lesions in the corpus callosum (upper; HE stain, $\times 20$ ) and evidence of axonal retraction balls in the internal capsule (lower; Bodian stain, $\times 200$ ) suggesting classical features of DAI.

mechanism is unknown. The platelet count is probably a sensitive indicator of the severity of brain damage. A platelet count below 100,000/ $\mu$ l suggests a high risk of developing intracranial hemorrhage. ? Patients with focal contusions and significant thrombocytopenia should therefore have repeat $\mathrm{CT}$ scans to detect DICH early.

Transcranial Doppler ultrasound is now widely used to detect intracranial hemodynamic phenomena because it is noninvasive and repeatable. ${ }^{1,4.19)} \mathrm{Al}$ though influences on the intracranial flow velocities are complex, there is a good correlation between the MCA flow velocity and cerebral hemispheric blood flow. ${ }^{4)}$ Intracranial hematoma causes increased ICP, which in turn causes compression of the cerebral veins, increased cerebrovascular resistance, and decreased cerebral blood flow. ${ }^{(5)}$ Our findings in focal brain injury may represent compression ischemia in the cerebral hemisphere due to increased vascular resistance. The MCA flow velocities decreased significantly when the $\mathrm{ICP}$ increased to $31 \mathrm{mmHg}$ or more and when CPP decreased to $40 \mathrm{mmHg}$ or less. This may indicate the thresholds for cerebral circulatory disturbance in focal brain injury. In patients with diffuse brain injury, however, the hemodynamic events were more complex. Decreased MCA flow velocity in diffuse brain injury may indicate reduced cerebral blood flow reflecting lower global metabolic requirements due to diffusely dam- aged neurons..$^{6,16)}$ The principal cause of DCS is possibly cerebrovascular dilatation causing increased cerebral blood flow. ${ }^{14,15)}$ The increase in MCA flow velocities observed in diffuse brain injury may represent such a hyperperfusion state. Another possible mechanism is narrowing of the MCA trunk because frequently associated subarachnoid hemorrhage may induce vasospasm. ${ }^{2.20)}$

DAI is the basic pathological lesion in fatal headinjured patients. ${ }^{2,39}$ Classical DAI is characterized by macroscopic lesions in the corpus callosum and dorsolateral quadrant of the brainstem and diffuse Wallerian degeneration of the white matter. ${ }^{2,3,9,211}$ However, Blumbergs et al. ${ }^{51}$ recently reported that the macroscopic "marker" lesions in the corpus callosum and the brainstem are only present in patients with very severe DAI. Our study showed that patients with both diffuse and focal brain injuries had macro- and microscopic evidence of DAI. We could identify different degrees of DAI in $50 \%$ of patients with focal brain injury, and quite probably focal brain injury is associated with DAI. Sahuquillo-Barris et al ${ }^{18)}$ also reported recently that DAI is found most often in SDH. TSAH cases had minimum brainstem injury without histological evidence of DAI, possibly because of their short survival time. Fatal TSAH cases may therefore have associated severe brainstem dysfunction. ${ }^{201}$ DAI of varying severity is the common subjacent lesion in pa- 
tients with severe head injury. However, diffuse and focal brain injuries include multiple lesion types and the final outcome varies greatly according to the lesion type.

\section{References}

1) Aaslid R, Markwalder TM, Nores $\mathrm{H}$ : Noninvasive transcranial Doppler ultrasound recording flow velocity in basal cerebral arteries. $J$ Neurosurg 57: 769777,1982

2) Adams JH, Graham DI, Murray LS, Scott G: Diffuse axonal injury due to nonmissile head injury in humans: An analysis of 45 cases. Ann Neurol 12: $557-563,1982$

3) Adams JH, Mitchell DE, Graham DI, Doyle D: Diffuse brain damage of immediate impact type: Its relationship to primary brainstem damage in head injury. Brain 100: 489-502, 1977

4) Bishop CCR, Dowell S, Rutt D, Browse WL: Transcranial Doppler measurement of middle cerebral artery blood flow velocity: A validation study. Stroke 17: 913-915, 1986

5) Blumbergs PC, Jones NR, North JB: Diffuse axonal injury in head trauma. $J$ Neurol Neurosurg Psychiatry 52: 838-841, 1989

6) Bruce DA, Langfitt TW, Miller JD, Shutz H, Valpalahti MP, Stanek A, Goldberg H: Regional cerebral blood flow, intracranial pressure and brain metabolism in comatose patients. $J$ Neurosurg 38: 131-144, 1973

7) Chan K-H, Mann KS, Chan TK: The significance of thrombocytopenia in the development of postoperative intracranial hematoma. I Neurosurg 71: 38-41, 1989

8) Gennarelli TA, Spielman GM, Langfitt TW, Gildenberg PL, Harrington T, Jane JA, Marshall LF, Miller JD, Pitts LH: Influence of the type of intracranial lesion on outcome from severe head injury. $J$ Neurosurg 56: 26-32, 1982

9) Gennarelli TA, Thibault LE, Adams JH, Graham DI, Thompson CJ, Marcincin RP: Diffuse axonal injury and traumatic coma in the primate. Ann Neurol 12: $564-574,1983$

10) Graham DI, Ford I, Adams JH, Doyle D, Teasdale GM, Lawrence AE, Mclellan DR: Ischemic brain damage is still common in fatal non-missile head injury. J Neurol Neurosurg Psychiatry 52: 346-350, 1989

11) Hassler W, Steinmetz H, Gawlowski J: Transcranial Doppler ultrasonography in raised intracranial pressure and in intracranial circulatory arrest. $J$ Neurosurg 68: 745-751, 1988
12) Jennet B, Bond $M$ : Assessment of outcome after severe brain damage. A practical scale. Lancet 1: 480-484, 1975

13) Kaufman HH, Hui KS, Mattson JC, Borit A, Childs TL, Hoots WK, Bernstein DP, Mekela ME, Wagner KA, Kahan BD, Gildenberg PL: Clinicopathological correlations of disseminated intravascular coagulation in patients with head injury. Neurosurgery 15 : $34-42,1984$

14) Langfitt TW, Gennarelli TA, Obrist WD, Bruce DA, Zimmerman RA: Prospect for the future in the diagnosis and management of head injury: Pathophysiology imaging, and population-based studies. Clin Neurosurg 29: 353-376, 1982

15) Miller JD: Physiology of trauma. Clin Neurosurg 29: $103-130,1982$

16) Obrist WD, Langfitt TW, Jaggi JL, Cruz J, Gennarelli TA: Cerebral blood flow and metabolism in comatose patients with acute head injury. $J$ Neurosurg 61: 241-253, 1984

17) Olson JD, Kaufman HH, Moake J, O'Gorman TW, Hoots K, Wagner K, Brown CK, Gildenberg PL: The incidence and significance of hemostatic abnormalities in patients with head injuries. Neurosurgery 24: $825-832,1989$

18) Sahuquillo-Barris J, Lamarca-Ciuro J, VilaitaCastan J, Rubio-Garcia E, Rodriguez-Pazos M: Acute subdural hematoma and diffuse axonal injury after severe head trauma. $J$ Neurosurg 68: 849-900, 1988

19) Shigemori M, Nakashima H, Moriyama $T$, Tokutomi T, Nishio N, Harada K, Kuramoto S: Noninvasive study of critical thresholds of intracranial pressure (ICP) and cerebral perfusion pressure (CPP) for cerebral circulation and brain function. Neurol Res 11: 165-168, 1989

20) Shigemori $M$, Tokutomi $T$, Hirohata $M$, Maruiwa $H$, Kaku N, Kuramoto S: Clinical significance of traumatic subarachnoid hemorrhage. Neurol Med Chir (Tokyo) 30: 396-400, 1990

21) Strich SJ: Diffuse degeneration of the cerebral white matter in severe dementia following head injury. $J$ Neurol Neurosurg Psychiat 19: 163-185, 1956

22) Teasdale G, Jennett B: Assessment of coma and impaired consciousness. A practical scale. Lancet 2: 8184,1974

Address reprint requests to: M. Shigemori, M.D., Department of Neurosurgery, Kurume University School of Medicine, 67 Asahi-machi, Kurume, Fukuoka 830, Japan. 